\title{
SELECTIVE MATE CHOICE BY FEMALES OF HARPOBITTACUS AUSTRALIS (MECOPTERA: BITTACIDAE)*
}

\author{
BY JoHN ALCOCK \\ Department of Zoology \\ Arizona State University, Tempe, AZ 85281
}

The use of nuptial gifts in courtship is a relatively rare phenomenon among insects but it is well developed in the Bittacidae where it has been studied in detail by Thornhill $(1976,1977,1979)$. In an investigation of Hylobittacus apicalis Thornhill (1976) demonstrated that females exercise choice in the selection of mates, preferring those that offer superior gifts; males that gave their mates large nutritious prey were permitted to copulate longer and transfer more sperm than males that offered small or unpalatable food presents. This paper outlines limited evidence that the duration of feeding and copulation by females of Australian mecopteran, Harpobittacus australis $\mathrm{Klug}$, is also linked to the quality of the nuptial gifts provided by the male.

\section{METHODS}

The species was studied in Warrumbungle National Park in northern New South Wales between 18-23 December 1978, a period of dry, warm weather when insects were active. Males and females appeared in the late morning and afternoon and perched on flowers, grasses and shrubs on a hillside by a small brook. I searched for males that were carrying a prey present, and upon finding one remained with it until the prey was discarded or until the insect moved and was lost to sight. As soon as a male was detected, I estimated the length of the prey in $\mathrm{mm}$, recorded the manner in which it was carried and made notes on any social interactions that occurred.

\section{RESULTS}

My observations of the sexual behavior of $H$. australis are in general agreement with those of Bornemissza (1966). Males carry nuptial gifts impaled on the beak or gripped with the hind tarsi

*Manuscript received by the editor November 2, 1979. 
while they hang from a perch with their front legs. Prey carried by the hindlegs had a mean estimated length of $8.8 \mathrm{~mm}(\mathrm{~N}=9)$ and included three bulky moths and one large lepidopterous larva. Prey pierced by the beak averaged $3.8 \mathrm{~mm}$ in length $(\mathrm{N}=11)$ and consisted entirely of delicate mirids and various soft-winged beetles.

Males with prey release a sex pheromone from glands in the posterior abdomen, an attractant that draws both males and females to them. In $19.5 \mathrm{hr}$ of observation, I recorded 10 male-male encounters and 31 male-female interactions. Male visitors uniformly attempted to steal the prey from the calling male and succeeded on two occasions. Prey piracy by males is common among bittacids (Thornhill 1979). Some females may also visit calling males solely to secure a food gift. One male-female interaction ended when the female removed the prey from the male and flew away. In another case, the female probed the male's prey for about $3 \mathrm{~min}$ after coming to his perch; the male attempted without success to effect a copulation and eventually a tussle for control of the prey ensued leading the pair to tumble off the perch and onto the ground. The female left; the male returned to his perch and probed the prey briefly before discarding it, apparently because the female had drained it of its contents.

In more typical interactions between males and females, the arriving female alighted causing the male to transfer the prey to his mouthparts. In my observations, unlike those of Bornemissza (1966) the female usually probed nuptial gift briefly with her beak $(\mathrm{N}=$ 26 ); on only three occasions a female refrained from "testing" the prey and all three involved unusually large nuptial gifts whose potential value might have ben assessed visually. As the female probed the gift, the male attempted to couple with her. In fifteen cases, the female refused to permit mating to occur, withdrawing from the male after the initial probe of his present.

In cases in which copulation occurred the male usually succeeded in pulling the prey from the female with his hindlegs shortly after insertion of his genitalia. The female, which had been facing the male in this initial phase of the interaction, would then drop down so that the bodies of the copulating pair formed an " $L$ ". (The average time from the start of an encounter to assumption of the " $L$ " position was $3.1 \mathrm{~min}$.).

While the female hung below the male she employed her hindlegs to pull vigorously at the male's hindlegs which were holding the prey 
away from the female's mouthparts. Males appeared reluctant to extend their legs and so permit the female to feed. The time required for the female to draw the nuptial gift to her averaged $0.95 \mathrm{~min}$ with a maximum of $4.6 \mathrm{~min}(\mathrm{~N}=11)$. When the male's legs were fully extended the female could reach the prey with her mouthparts; she fed upon it for as little as $1 \mathrm{~min}$ to as much as $17.25 \mathrm{~min}$. Immediately upon cessation of feeding the female disengaged from her partner and flew off.

\section{Selective Mate Choice by Females}

It seems likely that the probing of the prey by the female at the start of an encounter between the sexes permits the female to assess the nutritional/caloric value of the male's present. Females offered small prey or insects that had been consumed by an earlier partner of the male frequently rejected the male outright, leaving before copulation could begin. If we consider the first observed reaction of a female to a prey offered by a male, copulation occurred only once in ten cases in which the prey was a tiny 3-4 mm mirid or beetle. In contrast, if the prey were estimated to be $6 \mathrm{~mm}$ or larger, mating occurred in 8 of 10 cases $\left(\chi^{2}=7.3, \mathrm{P}<.05\right)$.

Five of twenty prey were offered to more than one (2-4) females in sequence. All five prey were $6 \mathrm{~mm}$ or larger. In one case, the prey was discarded by the male immediately after the second of two lengthy copulations. In the remaining four cases, the male dropped his gift only after it had been probed and rejected by a female, presumably because she found it an empty husk whose contents had been removed by earlier females.

Thus the quality of the nuptial gift must be of a certain minimum standard if the female is to permit the male to copulate with her at all. In addition, Bornemissza (1966) felt that the size of the prey was related to the duration of copulation in $H$. australis. Table 1 shows that there is indeed a correlation between the estimated size of a prey and (1) the duration of the feeding phase of copulation and (2) the overall length of the copulation. Large food items evidently contain within them sufficient materials to keep the female occupied for some time, during which period the male presumably transfers sperm to her.

Still more support for the hypothesis that the food value of the gift determines how long a female will feed on the prey and therefore how long she will copulate comes from comparisons of the response 
of several females offered the same prey. In the three cases in which a male presented the same food item to three different females, copulation lengths were (a) 10.2, 7.8, and $0 \mathrm{~min}$, (b) 15.7, 17.2, and 0 min, and (c) 12.3, 3.8 and 0 min and the feeding phase lasted (a) 10.2, 4.8, and $0 \mathrm{~min}$, (b) 15.3, 14.8, and $0 \mathrm{~min}$, and (c) $12.3,3.8$ and 0 min.

Table I. The relation between the estimated length of the prey offered a female as a nuptial gift and the time that she fed upon the prey and the duration of copulation. ${ }^{1}$

\begin{tabular}{crcrcr}
\hline $\begin{array}{c}\text { Size of } \\
\text { gift }\end{array}$ & $\mathrm{N}$ & $\begin{array}{c}\text { Mean time of } \\
\text { feeding }\end{array}$ & Range & $\begin{array}{c}\text { Mean time of } \\
\text { copulation }\end{array}$ & Range \\
\hline & & & & & \\
$3-4 \mathrm{~mm}$ & 10 & $0.2 \mathrm{~min}$ & $0-1.8$ & $1.1 \mathrm{~min}$ & $0-8.0$ \\
$6-8 \mathrm{~mm}$ & 6 & 3.6 & $0-17.3$ & 6.2 & $0-19.3$ \\
$10-14 \mathrm{~mm}$ & 4 & 12.3 & $10.2-15.3$ & 13.7 & $10.2-16.8$ \\
\hline
\end{tabular}

Correlation between size of prey and feeding time, $r=0.70, p<.01$

Correlation between size of prey and copulation time, $r=0.62, p<.01$

'Data collected from the first observed interaction between a male carrying a nuptial present and a female.

\section{DisCUSSION}

The species of bittacids studied to date exhibit reasonably similar sexual behavior including the use of pheromones, nuptial gift giving, female sampling of the present before copulation, and copulations of variable length but with means of about $10-20 \mathrm{~min}$ (Thornhill, 1977). An unusual feature of the mating behavior of Harpobittacus is the removal of the prey from the female by the male for a short period after the onset of copulation. In some other bittacids females feed continuously on the nuptial gift. The apparent struggle between copulating partners of $H$. australis for possession of the prey demonstrates the male and female interests are not identical. Perhaps the risk of prey thievery by females favors males that are cautious about relinquishing their valuable presents; perhaps they refuse to let potential mates feed until sperm have begun to be accepted by their partners.

Sperm transfer in Hylobittacus apicalis is proportional to the duration of copulation (up to about $20 \mathrm{~min}$ ) and it would not be surprising if this were also true for $H$. australis, whose females feed 
in copulo for from 1-17 min. Certainly females discriminate among males on the basis of edible volume of the nuptial gift, refusing to couple at all with males offering very small presents or prey that have been drained by previous mates. This mecopteran, therefore, probably provides another example of a species whose females exercise mate choice, accepting sperm preferentially from individuals that make a large parental investment in the form of a food gift that may promote egg development or female survival.

\section{ACKNOWLEDGEMENTS}

This study was conducted while the author was a visiting lecturer at Monash University. I thank the members of the Zoology Department at Monash for their help, my sons Joey and Nicky for their assistance with field work, and Randy Thornhill for reading the manuscript.

Bornemissza, G. F.

\section{REFERENCES}

1966. Observations on the hunting and mating behaviour of two species of scorpion flies (Bittacidae: Mecoptera). Aust. J. Zool. 14: 371-382.

THORNHILL, R.

1976. Sexual selection and nuptial feeding behavior in Bittacus apicalis (Insecta: Mecoptera). Amer. Nat. 110: 529-548.

1977. The comparative predatory and sexual behavior of hanging flies (Mecoptera: Bittacidae). Occ. Papers Mus. Zool., Univ. Mich. 677: 1-43.

1979. Adaptive female-mimicking behavior in a scorpionfly. Science 205: 412-414. 

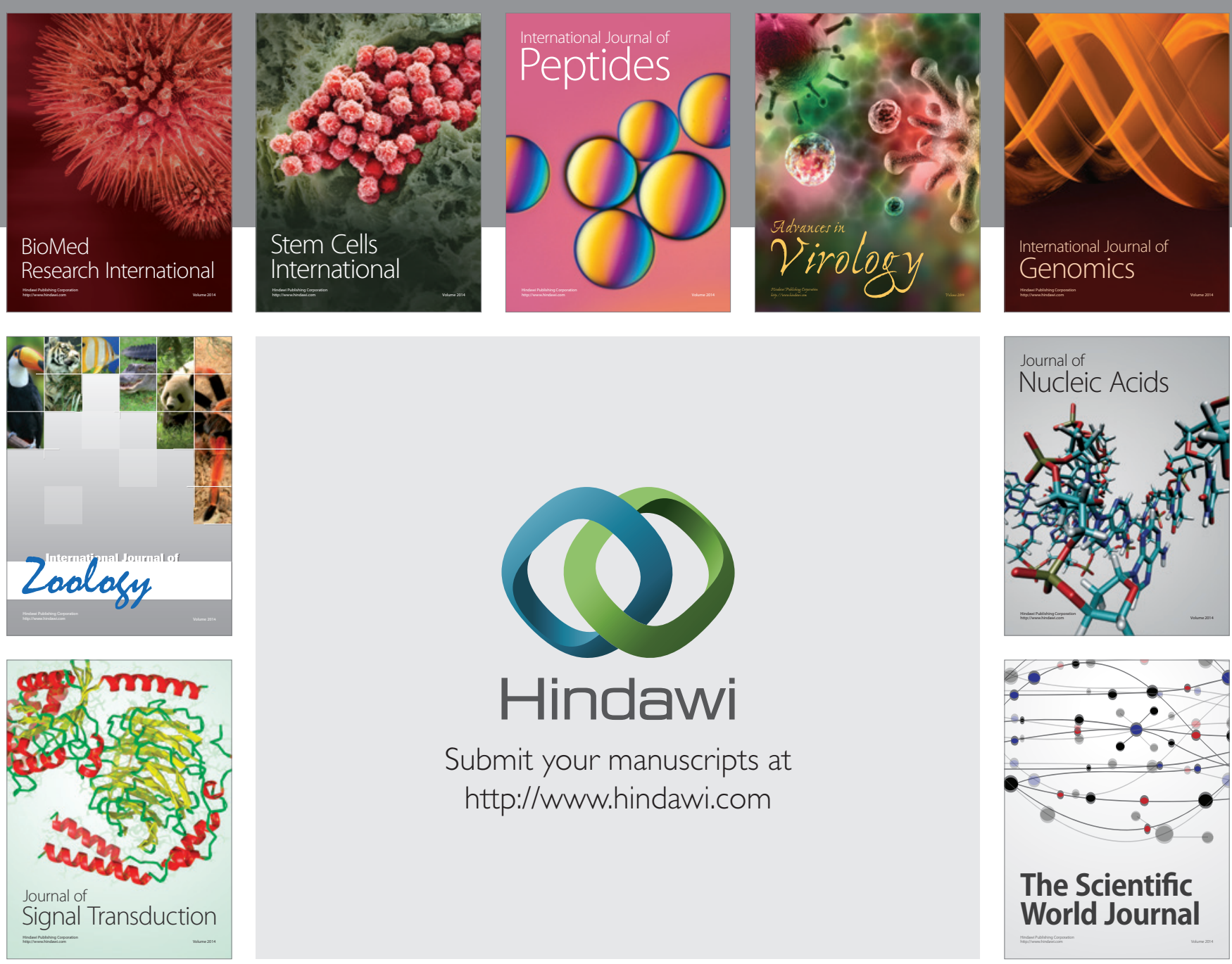

Submit your manuscripts at

http://www.hindawi.com
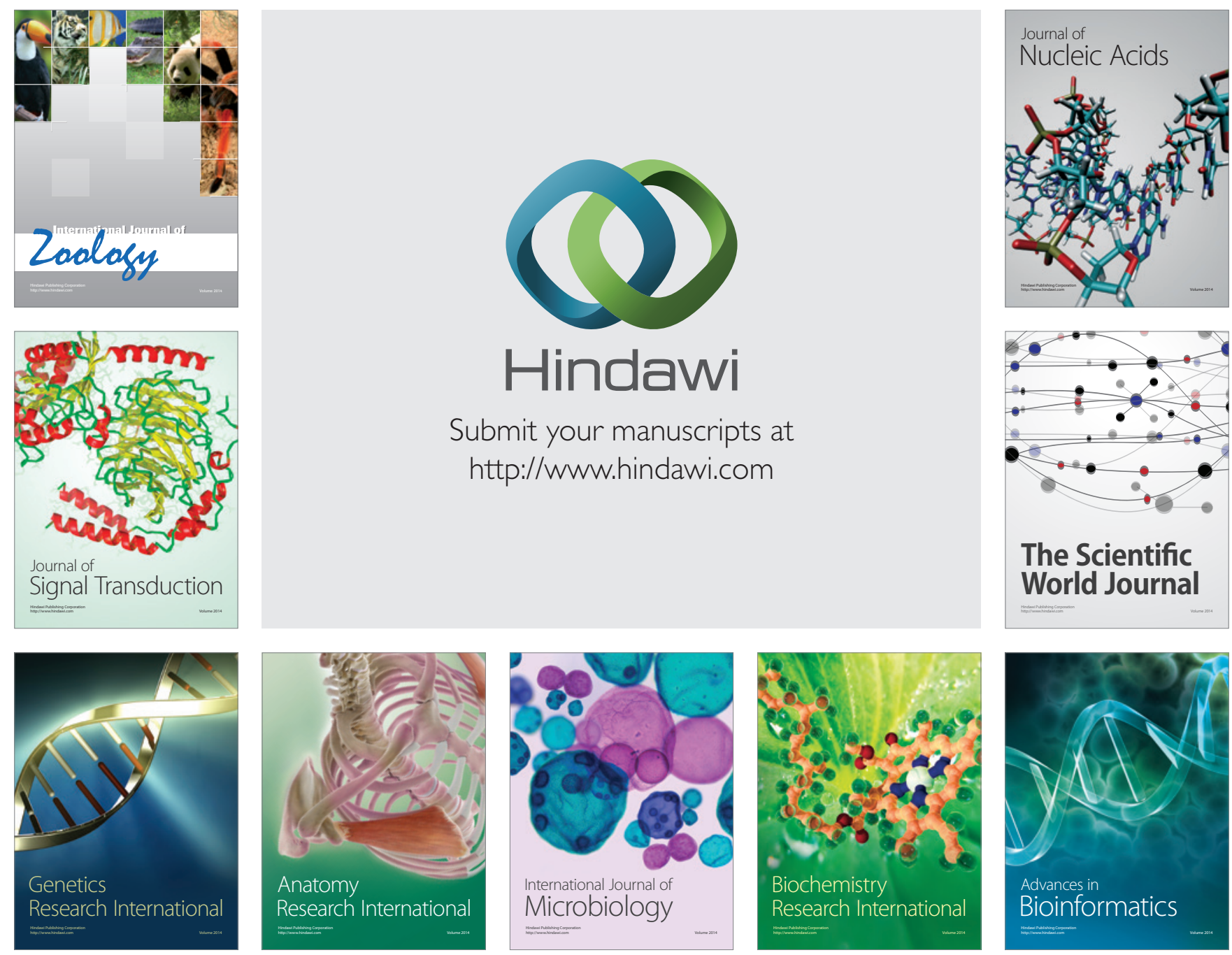

The Scientific World Journal
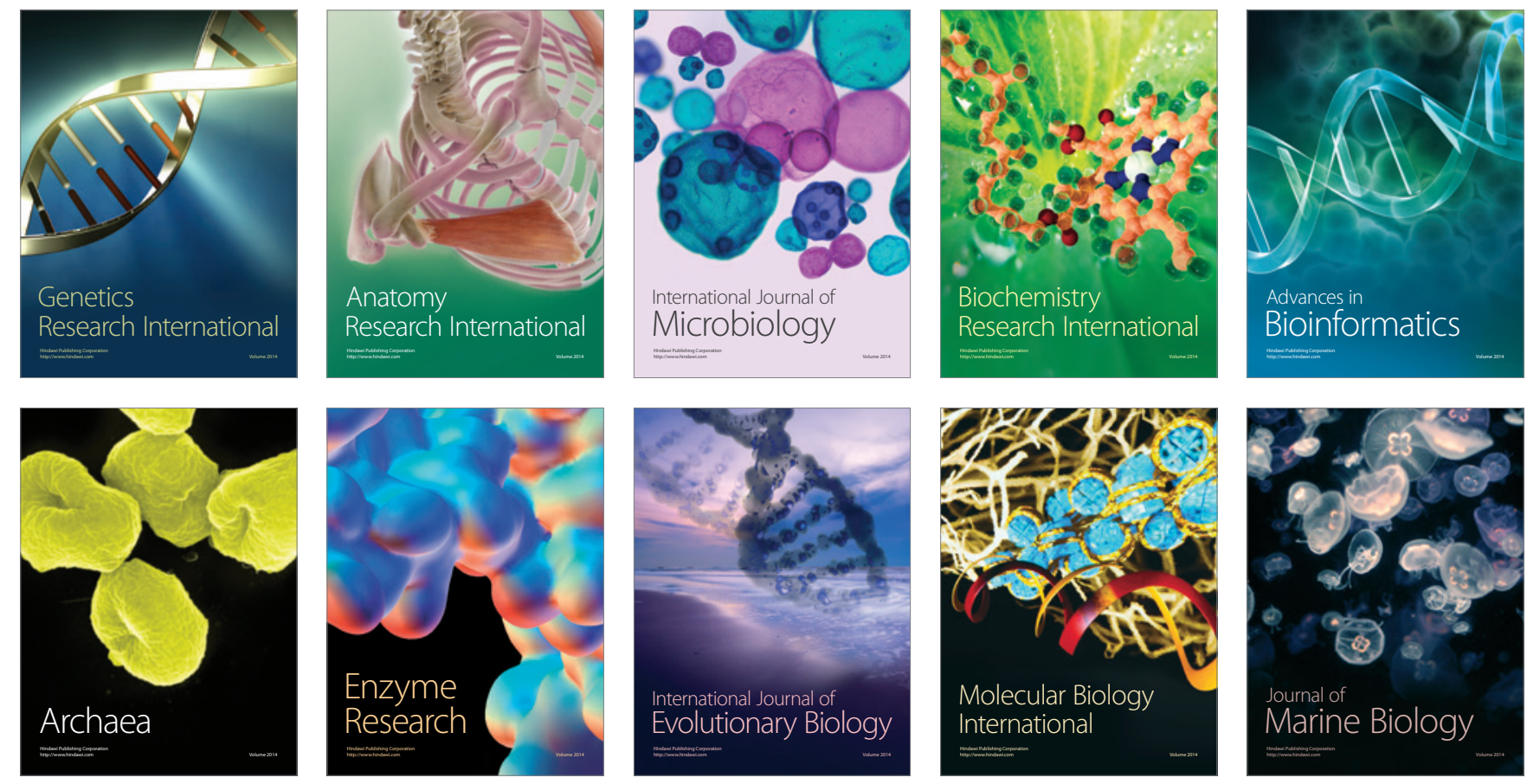